\title{
Multiple Stage Pentaquadrupole Mass Spectrometry for Generation and Characterization of Gas-Phase Ionic Species. The Case of the $\mathrm{PyC}_{2} \mathrm{H}_{5}^{+\cdot}$ Isomers
}

\author{
Ana Elisa P. M. Sorrilha, Fábio C. Gozzo, Regina S. Pimpim, and \\ Marcos N. Eberlin \\ State University of Campinas-CNICAMP, Institute of Chemistry, Campinas, Brazil
}

Eleven isomers with the $\mathrm{PyC}_{2} \mathrm{H}_{5}^{+\cdot}$ composition, which include three conventional (1-3) and eight distonic radical cations (4-11), have been generated and in most cases successfully characterized in the gas phase via tandem-in-space multiple-stage pentaquadrupole MS $^{2}$ and MS $^{3}$ experiments. The three conventional radical cations, that is, the ionized ethylpyridines $\mathrm{C}_{2} \mathrm{H}_{5}-\mathrm{C}_{5} \mathrm{H}_{4} \mathrm{~N}^{+\cdot}(1-3)$, were generated via direct $70-\mathrm{eV}$ electron ionization of the neutrals, whereas sequences of chemical ionization and collision-induced dissociation (CID) or massselected ion-molecule reactions were used to generate the distonic ions $\mathrm{H}_{2} \mathrm{C}-\mathrm{C}_{5} \mathrm{H}_{4} \mathrm{~N}^{+}-\mathrm{CH}_{3}$ (4-6), $\mathrm{CH}_{3}-\mathrm{C}_{5} \mathrm{H}_{4} \mathrm{~N}^{+}-\mathrm{CH}_{2}^{-}(7-9), \mathrm{C}_{5} \mathrm{H}_{5} \mathrm{~N}^{+}-\mathrm{CH}_{2} \mathrm{CH}_{2}^{-}$(10), and $\mathrm{C}_{5} \mathrm{H}_{5} \mathrm{~N}^{+}-\mathrm{CH}-\mathrm{CH}_{3}$ (11). Unique features of the low-energy (15-eV) CID and ion-molecule reaction chemistry with the diradical oxygen molecule of the isomers were used for their structural characterization. All the ion-molecule reaction products of a mass-selected ion, each associated with its corresponding CID fragments, were collected in a single three-dimensional mass spectrum. Ab initio calculations at the ROMP2/6-31G(d, p) $/ / 6-31 G(d, p)+$ $\mathrm{ZPE}$ level of theory were performed to estimate the energetics involved in interconversions within the $\mathrm{PyC}_{2} \mathrm{H}_{5}^{+}$. system, which provided theoretical support for facile $4 \rightleftharpoons 7$ interconversion evidenced in both CID and ion-molecule reaction experiments. The ab initio spin densities for the $\alpha$-distonic ions 4-9 and 11 were found to be largely on the methylene or methyne formal radical sites, which thus ruled out substantial odd-spin delocalization throughout the neighboring pyridine ring. However, only 8 and 9 (and 10) react extensively with oxygen by radical coupling, hence high spin densities on the radical site of the distonic ions do not necessarily lead to radical coupling reaction with oxygen. The very typical "spatially separated" ab initio charge and spin densities of 4-11 were used to classify them as distonic ions, whereas 1-3 show, as expected, "localized" electronic structures characteristic of conventional radical ions. (c) 1996 American Society for Mass Spectrometry (J Am Soc Mass Spectrom 1996, 7, 1126-1137)

$\mathrm{N}$ ondissociative and dissociative electron ionization (EI) or chemical ionization (CI) of neutral molecules performed in mass spectrometric environments are the main and most convenient routes for generation of a large variety of ionic species in the gas phase [1]. However, these ionization techniques sometimes can be unsuccessful in generation of specific ions or classes of ions. Collision-induced dissociation (CID) [2] and ion-molecule reactions with massselected ions (here termed as "mass-selected" ion-molecule reactions) [3] are very useful complementary techniques for the generation of many ionic species, in particular of those inaccessible by direct ionization of a neutral. These mass spectrometric tech-

Address reprint requests to Dr. Marcos N. Eberlin, State University of Campinas, Institute of Chemistry, CP 6154 Campinas, SP 13083-970 Brazil. niques together offer powerful and elegant tools for the generation of a large variety of isolated long-lived ionic species in the gas phase.

CID and mass-selected ion-molecule reactions are also powerful tools for the elucidation of ion structures. Although CID has become the standard method for ion characterization [2], mass-selected ion-molecule reactions also have made an important contribution to this field [3]. The judicious application of either of these techniques or a combination of both has increased considerably the accuracy of structural assignment of gas-phase ions. Additionally, some ion-molecule reactions have been shown to be specific or "structurally diagnostic" for a class of ions and thus provide general methods for their gas-phase characterization. For instance, many acylium [4] and their structurally related sulfinyl cations [5] have been shown to display a general "ionic transketalization" reaction 
with 1,3-dioxolanes, whereas distonic ions of several types react selectively with methyl diselenide by $\mathrm{SeCH}_{3}$ abstraction [6].

Multiple-stage mass spectrometry $\left(\mathrm{MS}^{n}\right)$ [7] have substantially increased the strength and usefulness of CID and ion-molecule reactions for generation, structural elucidation, and studies of the gas-phase chemistry of isolated ionic species. Application of $\mathrm{MS}^{n}$ techniques enables ions to be mass-selected and reacted, and their product ion characterization to be achieved by further CID and/or structurally diagnostic massselected ion-molecule reactions. Pentaquadrupole (QqQqQ) mass spectrometers [8] (Figure 1) are particularly useful in this field: they allow the full range of $\mathrm{MS}^{2}$ and $\mathrm{MS}^{3}$ experiments [9] to be accessed and allow either CID or ion-molecule reactions to be studied in either reaction region (q). Additionally, their usefulness is increased by the simplicity and speed of multidimensional mass spectra acquisition and the power of multidimensional (three- and four-dimensional) mass spectra to provide a broad view of the whole ion-molecule process [8b]. Application of the reaction intermediate $\mathrm{MS}^{3}$ scan, for instance, reveals the reaction intermediates in CID [8a] or ion-molecule processes [10a], whereas in a single four-dimensional (three mass-to-charge ratio and one intensity axis) spectrum, the complete series of ion-molecule products from all the ions of a specific precursor can be collected, where each product is associated with its corresponding CID fragments [8b]. The inverse combination, that is, all the selected CID fragments of specific precursor ions, where each fragment is associated with its ion-molecule products, also has been collected in single three-dimensional spectra [10c]. Implementation of simultaneous linked scanning modes for the three mass-analyzing quadrupoles enables several consecutive neutral gain-neutral loss (or related) experiments to be performed, which thus permits the elaboration of very selective structural tests that combine

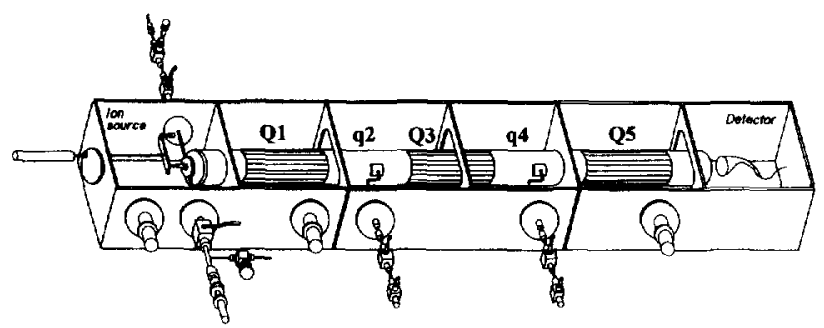

Figure 1. The Extrel pentaquadrupole mass spectrometer, a convenient "laboratory" for gas-phase ion chemistry studies, with its three mass-analyzer quadrupoles (Q1, Q3, and Q5) and two reaction chambers ( $\mathrm{q} 2$ and $\mathrm{q} 4)$. In a typical ion-molecule reaction experiment, ions are generated in the ion source, purified (mass-selected) by Q1, and reacted with a neutral gas introduced in q2 under controlled conditions (collision energy and pressure). Each of the product ions then can be mass-selected subsequently by Q3 and structurally analyzed by either collisional dissociation or structurally diagnostic ion-molecule reactions in $q 4$, while the products formed in these processes are disclosed by scanning Q5. Adapted from ref $5 \mathrm{~b}$. ion-molecule reactions and CID processes [8b]. The usefulness of the pentaquadrupole for detailed gasphase ion-chemistry studies was demonstrated recently $[5,8 b, 10]$.

The $\mathrm{PyC}_{2} \mathrm{H}_{5}^{+\cdot}$ ions [11] constitute a rich system of isomers that includes a series of distonic ions [12], most of which have not been generated or characterized. Additionally, the classification of several $\mathrm{PyC}_{2} \mathrm{H}_{5}^{+\cdot}$ ions (1-11) as distonic or conventional radical cations is not straightforward. The structurally and chemically fascinating class of distonic radical cations (from the Greek diestos and the Latin distans, which mean separate [13]) are classified by the widely accepted definition [12] as ions that display "spatially separated" charge and spin sites; in other words, such sites should be formally localized at different atoms or group of atoms in a conventional valence bond description. This definition is, however, heavily dependent on our interpretation of the best representation of ionic structures based on valence bond theory and the localized electron model [14]. Ambiguous classifications occur in some more complex cases, particularly for those ions that bear no formally separated charge and radical sites. The original [13] and equivalent definition of distonic ions as species that arise from removal of an electron from a zwitterion or a diradical do not satisfactorily solve the problem in these more complex cases because it merely moves the uncertainties to the classification of their neutral precursors, as exemplified in the present work particularly for the case of ions 4 and 6.<smiles>CCc1ccccn1</smiles><smiles>CCc1cccnc1</smiles>

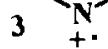<smiles>[CH2]c1cccc[n+]1C</smiles><smiles>[CH2]c1ccc[n+](C)c1</smiles><smiles>Cc1cccc[n+]1C</smiles><smiles>Cc1ccc[n+](C)c1</smiles><smiles>Cc1cc[n+](C)cc1</smiles><smiles>CC[n+]1ccccc1</smiles><smiles>CC[n+]1ccccc1</smiles>

The present study takes advantage of the outstanding capabilities of the Extrel pentaquadrupole mass spectrometer to perform fast and "high-transmission" 
[8b] multiple-stage ( $\mathrm{MS}^{2}$ and $\mathrm{MS}^{3}$ ) mass spectrometric experiments, and combines or adapts several previously well-elaborated strategies based on combinations of EI, CI, CID, and/or ion-molecule reactions to generate a total of $11 \mathrm{PyC}_{2} \mathrm{H}_{5}^{+\cdot}$ isomers (1-11) and, in most cases, to characterize them unambiguously in the gas phase. A three-dimensional triple-stage $\left(\mathrm{MS}^{3}\right)$ mass spectrum [9] was acquired and showed remarkable usefulness in presentation of a detailed picture of an ion-molecule process. $\mathrm{Ab}$ initio calculations also have been applied to evaluate the energetics involved in interconversions within the interesting $\mathrm{PyC}_{2} \mathrm{H}_{5}^{+\cdot}$ ionic system and to help classify the ions as distonic or conventional radical cations based on their $a b$ initio charge and spin densities.

\section{Experimental}

The experiments were performed via an Extrel (Pittsburgh, PA) pentaquadrupole mass spectrometer (Figure 1), which consists of three mass analyzing (Q1, Q3, Q5) and two reaction quadrupoles (q2, q4). Ion-molecule reactions were performed at near $0-\mathrm{eV}$ collision energy, whereas $\mathrm{CID}$ employed 15-eV collisions with argon. The collision energies were calculated as the voltage difference between the ion source and the reaction quadrupole. For the $\mathrm{MS}^{2}$ experiments, Q1 was used to mass-select the desirable reactant ion generated in the ion source. After CID or ion-molecule reaction in $\mathrm{q} 2$, the product ion spectrum was recorded by Q5, while Q3 was operated in the nonanalyzing rf-only mode. For the two-dimensional $\mathrm{MS}^{3}$ experiments, a product ion generated in $\mathrm{q} 2$ was mass-selected in Q3 and reacted or dissociated further in q4, while Q5 was scanned to record the spectrum.

The three-dimensional triple-stage mass spectrum was acquired by generation of the $m / z$ in in the ion source (from 70-eV electron ionization of ethylene oxide) and mass-selection in Q1. Ion-molecule reactions with 2-methylpyridine in $\mathrm{q} 2$ and $\mathrm{CID}$ with argon in q4 then were performed, while both Q3 and Q5 were sequentially scanned to produce the threedimensional output. The sequential scanning was accomplished by stepping Q3 one mass at a time while Q5 was scanned along the entire mass range of interest at each setting of $Q 3$. A selective pre-scan procedure [8b] was used to speed up data acquisition by identification of the Q3 parent ions and scanning Q5 only while Q3 was set exactly at each of the pre-selected masses. For the $\mathrm{MS}^{3}$ experiments, the total pressures inside each differentially pumped region were typically $2 \times 10^{-6}$ (ion source), $8 \times 10^{-6}$ (q2), and $6 \times$ $10^{-5}$ torr ( $\left.\mathrm{q} 4\right)$, respectively, which were determined to correspond to multiple-collision conditions in both q2 and $\mathrm{q} 4$ [10]. More details of this instrument and its operating conditions were presented elsewhere [8b].

$\mathrm{Ab}$ initio molecular orbital calculations were carried out by using Gaussian94 [15]. The ionic structures were optimized at the restricted open-shell
Hartree-Fock (ROHF) level of theory by employing the polarization $6-31 \mathrm{G}(\mathrm{d}, \mathrm{p})$ basis set [16]. Improved energies were obtained by using single-point calculations at the 6-31G(d,p) level and incorporating valence electron correlations calculated by second-order Møller-Plesset (ROMP2) perturbation theory [17]. Harmonic vibrational frequencies were used to characterize the stationary points and to obtain the zero-point vibrational energies (ZPE). Xmol [18] was used to visualized the input and output structures.

\section{Results and Discussion}

\section{Generation of the $\mathrm{PyC}_{2} \mathrm{H}_{5}^{+{ }^{+}}$Isomers}

The conventional ions 1-3. The generation of this subcategory of $\mathrm{PyC}_{2} \mathrm{H}_{5}^{+\cdot}$ ions, that is, the three ionized ethylpyridines 1-3, is straightforward and was accomplished by direct 70-eV EI of their neutral, stable counterparts.

The distonic ions 4-11. Neutral precursors of distonic ions (i.e., ylides, diradicals, or zwitterionic molecules) are often unstable or difficult to access; hence these ions cannot be formed by direct ionization techniques. Many distonic ions, however, have been generated from spontaneous or collision-induced dissociation of large molecular ions, by fast structural rearrangements of conventional radical cations, or by ion-molecule reactions [12]. For the generation of 4-11, combination sequences of $\mathrm{EI}$ or $\mathrm{CI}, \mathrm{CID}$, and/or ion-molecule reactions were employed as described in the following text.

Ions 4-6. The interesting CI-CID sequence recently applied by Flammang and co-workers [19] to two $\mathrm{CH}_{2}-\mathrm{C}_{5} \mathrm{H}_{4} \mathrm{~N}^{+}-\mathrm{H}$ pyridinium ions was adapted to generate 4-6. These ions also can be formed by field ionization (FI) and EI of 1,2- and 1,4-dimethylpyridinium chloride, respectively [20]. In a $\mathrm{MS}^{2}$ experiment, the $\mathrm{N}$-methyl ethylpyridinium ions were generated in the ion source by $\mathrm{CH}_{3} \mathrm{ICI}$ of the corresponding ethylpyridines, mass-selected further in Q1, and then subjected to CID with argon in q2. Dissociations occur almost exclusively by loss of a methyl radical to yield 4-6 (Figure 2a). Generation via $\mathrm{CD}_{3} \mathrm{I} \mathrm{CI}$ and dissociation of the corresponding $\mathrm{N}-\mathrm{CD}_{3}$ isotopomers confirm formation of 4-6 (Figure 2b). Note the exclusive loss of $15 \mathrm{u}\left(\mathrm{CH}_{3}^{-}\right)$, which nicely confirms that the loss is of the side-chain methyl group (eq 1).

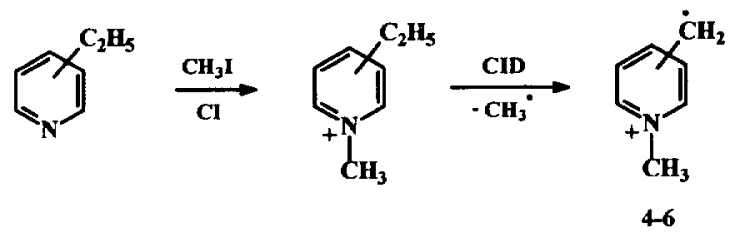




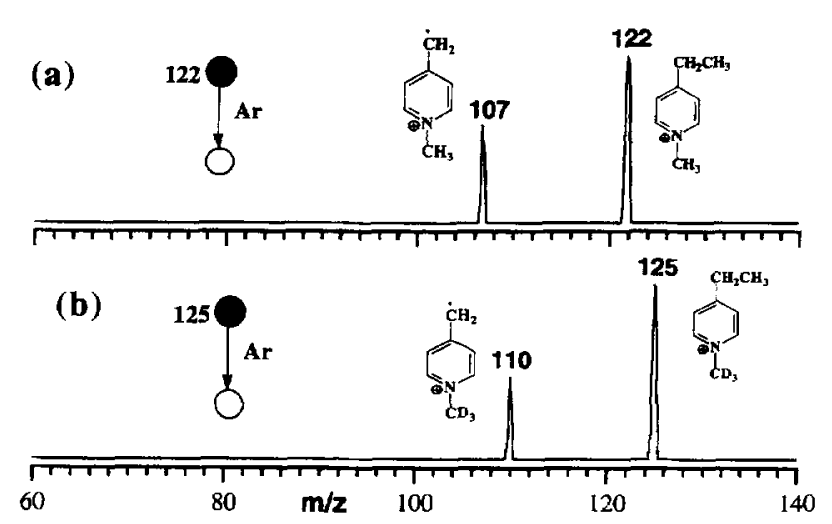

Figure 2. Double-stage CID product ion spectra of (a) $N$-methylated and (b) $\mathrm{N}-\mathrm{CD}_{3}$ 4-ethylpyridinium ions. Note the dissociation in both cases by methyl radical loss ( $15 \mathrm{u}$ ), which confirms that loss is of the side-chain methyl group.

IoNs 7-9. Ion-molecule reactions [21b] and CID experiments [10h, 11, 21] have unequivocally demonstrated that the $\alpha$-distonic ion $\mathrm{CH}_{2}-\mathrm{O}-\mathrm{CH}_{2}^{+}$reacts with pyridines extensively by $\mathrm{CH}_{2}^{+\cdot}$ transfer to the ring nitrogen, thus yielding $\alpha$-distonic $N$-methylene pyridinium ions. Generation of 7-9 was therefore accomplished by ion-molecule reactions between ${ }^{-} \mathrm{CH}_{2}-\mathrm{O}-\mathrm{CH}_{2}^{+}$and the three isomeric methyl pyridines (eq 2) performed either in the ion source (oxirane $\mathrm{CI}$ ) or by $\mathrm{MS}^{2}$ experiments. The typical product ion spectrum seen across the diagonal dashed line of the three-dimensional mass spectrum (Figure 3a), and the projected two-dimensional product ion spectrum (Figure $3 \mathrm{c}$ ) clearly show that the reactions yield abundant $\mathrm{CH}_{2}^{+\cdot}$ transfer product $(\mathrm{m} / z 107$ in the figures), presumably 7-9. A detailed description of the experimental setup used to acquire the three-dimensional spectrum (Figure 3a), and all the information that can be extracted from it is presented in the CID chemistry section that follows.

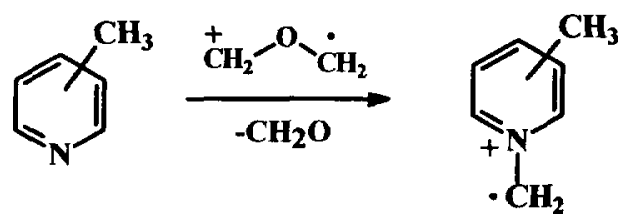

IoN 10. Ion-molecule reactions between massselected ionized pyridine and neutral ethylene (eq 3), which first were applied by Gross and co-workers [11] under $\mathrm{CI}$ and unique high-pressure Fourier transform mass spectrometry (FTMS) conditions [11], was used to produce the $\beta$-distonic ion 10. Figure 4 shows the whole sequence of $\operatorname{MS}^{n}(n=1,2,3)$ scans used to generate this ion and to study its gas-phase chemistry. Ionized pyridine was generated by $70-\mathrm{eV}$ EI of the neutral (Figure 4a), which was mass-selected further in Q1 (Figure $4 \mathrm{~b}$ ) and reacted with neutral ethylene in $\mathrm{q} 2$ (Figure 4c). The adduct (10) of $m / z 107$ is formed together with an ionic product of $m / z 106$, which is best rationalized as the $N$-vinyl pyridinium cation formed by loss of a hydrogen atom from 10. It is interesting to note that higher pressures of ethylene in $q 2$, which intensify the number of low-energy collisions, minimize the hydrogen atom loss fragment $(\mathrm{m} / \mathrm{z}$ 106) while they increase the abundance of the adduct

(c)

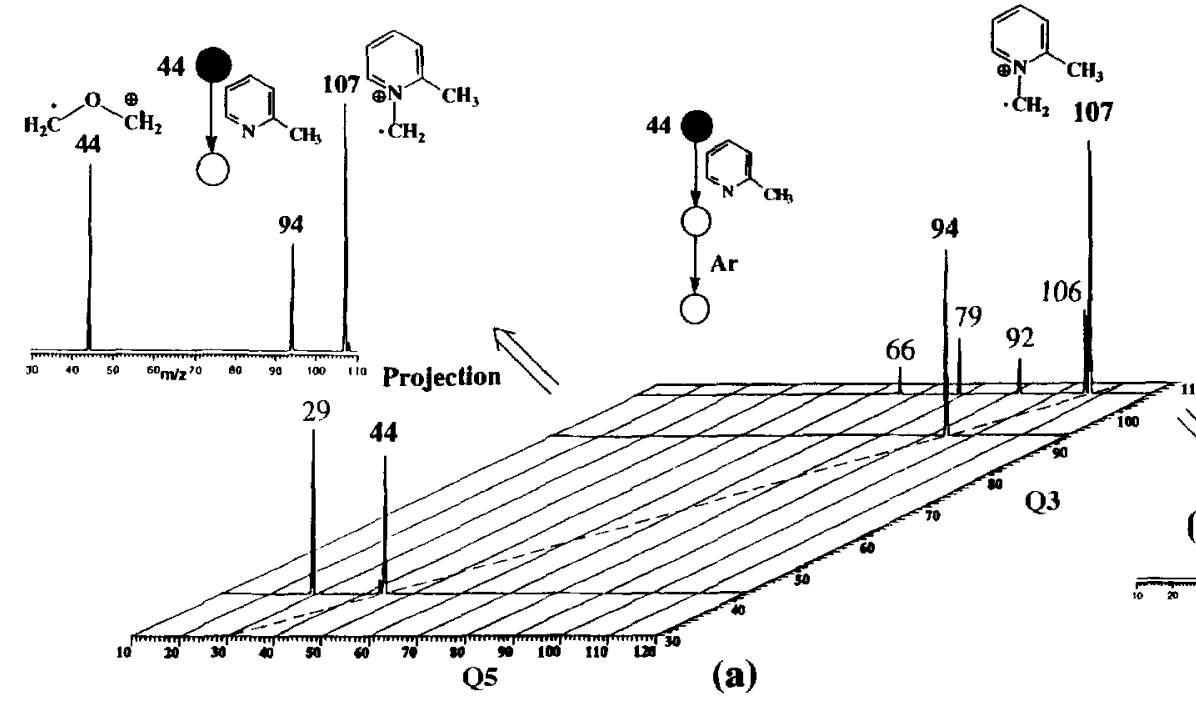

Figure 3. (a) Three-dimensional triple-stage intermediate-product domain spectrum for the ion-molecule reaction between ${ }^{\circ} \mathrm{CH}_{2}-\mathrm{O}-\mathrm{CH}_{2}^{+}(\mathrm{m} / z$ 44) and 2-methylpyridine. All the reaction products (bold numerals) are displayed along the diagonal dashed line (equal Q3 and Q5 mass-to-charge ratios), whereas their corresponding 15-eV CID fragments are displayed along the horizontal Q5 axis. (b) Extracted two-dimensional triple-stage sequential product ion spectrum of the ionic product of $m / z \quad 107$ (7). (c) The reconstructed (by projection toward the Q3 axis) two-dimensional double-stage product ion spectrum. 


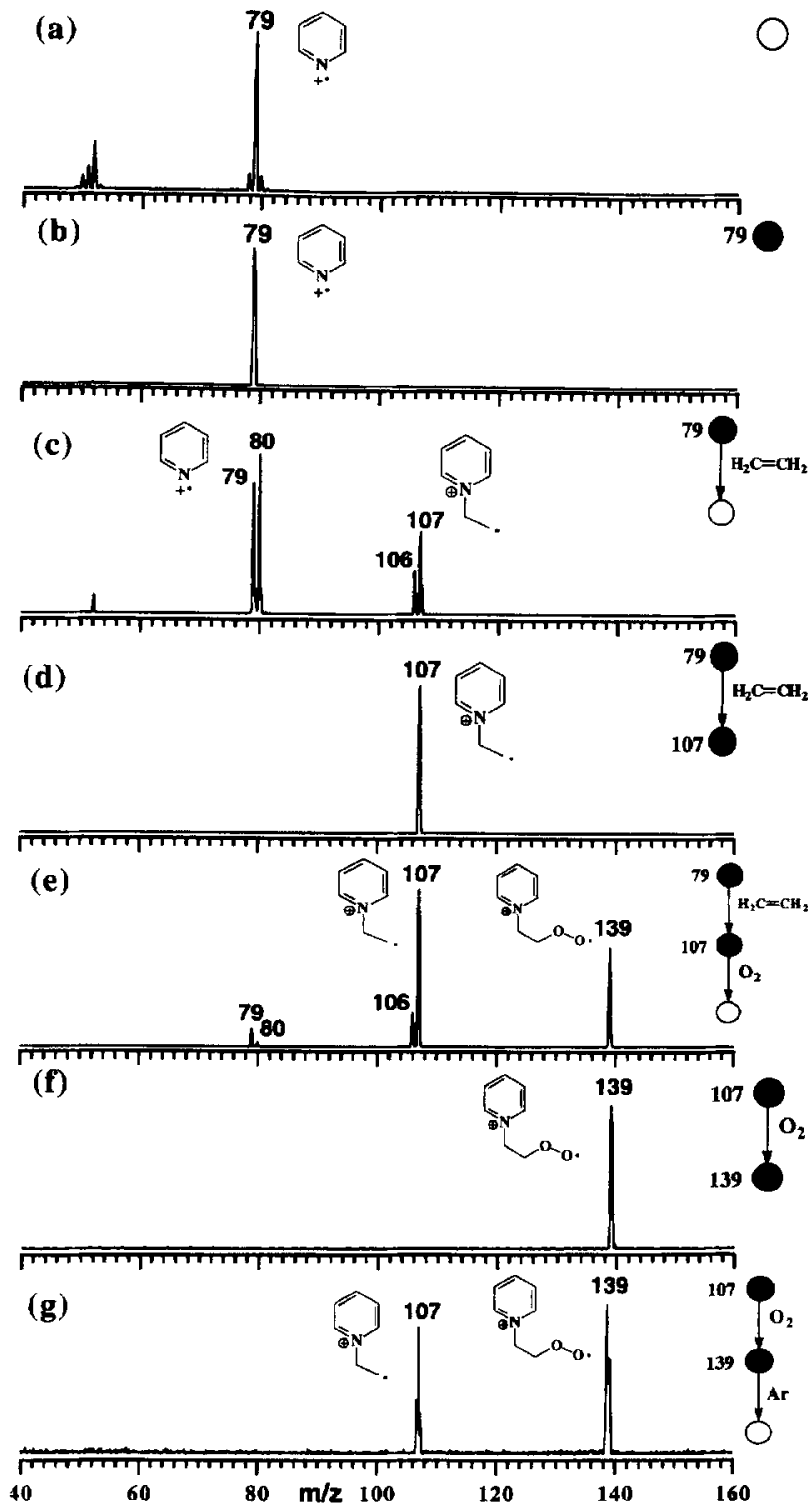

Figure 4. The whole sequence of pentaquadrupole $\mathrm{MS}^{n}$ ( $n=$ $1,2,3)$ scans applied to generate, isolate, and study the gas-phase chemistry of the $\beta$-distonic ion 10 . Ionized pyridine $(m / z 79)$ is (a) produced by $70-\mathrm{eV}$ EI of the neutral, (b) mass-selected by Q1, and (c) reacted further with ethylene in $\mathrm{q} 2$. The reaction product of $m / z 107(\mathbf{1 0})$ is then (d) mass-selected by Q3 and (e) reacted further with $\mathrm{O}_{2}$ in $q 4$, while $Q 5$ is scanned to acquire the triple-stage sequential product ion spectrum. To acquire the dissociation spectra of the oxygen adduct, $\mathbf{1 0}$ was generated in the ion source by ethylene $\mathrm{CI}$ of pyridine, reacted in $\mathrm{q} 2$ with oxygen, and (f) the adduct of $m / z 139$ was mass-selected in Q3 and dissociated further by $(\mathrm{g})$ CID with argon in $\mathrm{q} 4$.

$(m / z$ 107). This effect clearly indicates collisional cooling or stabilization of the adduct in a manner that is similar to that observed during high-pressure FTMS experiments [11]. These results also indicate that the high-pressure conditions that allow the observation of some relatively unstable ion-molecule reaction products under modified FTMS conditions can be reproduced closely in multiple-quadrupole mass spectrometers. It is also reasonable to consider that the multiple-collision conditions cause some collisional cooling of the reactant ion. It is worth noting that the opposite reaction (i.e., the reaction between massselected ionized ethylene and neutral pyridine) occurs predominantly by charge-exchange and proton transfer and does not form 10. The high efficiency of the ionized pyridine-neutral ethylene reaction also was observed via double resonance FTMS experiments [11].

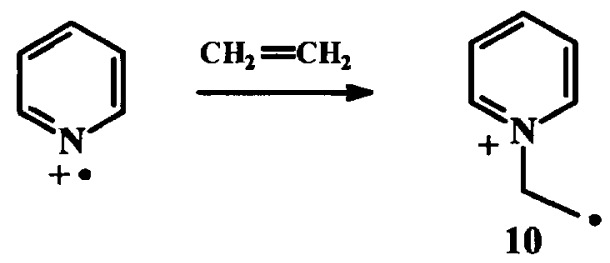

IoN 11. The $\alpha$-distonic ion $\mathbf{1 1}$ has been generated via ion-molecule reactions that involve $\mathrm{C}_{2} \mathrm{H}_{4}^{+\cdot}$ transfer from ionized methylcyclopropane to neutral pyridine [11]. It is known, however, that a significant portion of the $m / z$ 58 ionic population generated from 4-methyl1,3-dioxolane has the $\mathrm{C}-\mathrm{C}$ ring-opened form (i.e., the $\alpha$-distonic ion ${ }^{+} \mathrm{CH}_{2}-\mathrm{O}-\mathrm{CH}^{-}-\mathrm{CH}_{3}$ ) [22]. This ion, by analogy with the behavior of ${ }^{+} \mathrm{CH}_{2}-\mathrm{O}-\mathrm{CH}_{2}$, is expected to react with pyridine by both $\mathrm{CH}_{2}^{+\cdot}$ and $\mathrm{CHCH}_{3}^{+\cdot}$ transfers. Ion-molecule reactions between these $m / z 58$ ions and neutral pyridine were performed and led to reasonably abundant $\mathrm{CH}_{2}^{+\cdot}(\mathrm{m} / \mathrm{z}$ 93) and $\mathrm{C}_{2} \mathrm{H}_{4}^{+*}(11, m / z$ 107) transfer products at approximately the same abundances (eq 4).

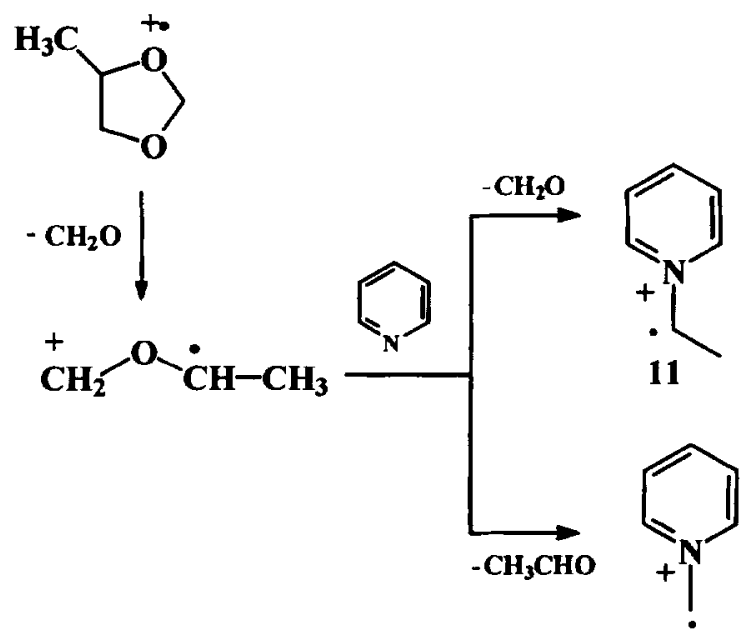

\section{Characterization of the Isomers}

Low-energy CID. The high-energy CID spectra of some of the $\mathrm{PyC}_{2} \mathrm{H}_{5}^{+}$ions can be used to differentiate them, as was recently reported [11]. Several characteristic features clearly distinguish 1 from 2 and 3 , whereas 2 and 3 display quite similar dissociation chemistry. Distinction between 10 and 11 by high-energy CID was 
shown to be possible also [11] and has as its basis a greater relative abundance of the $\mathrm{m} / \mathrm{z} 80$ fragment $\left(\mathrm{C}_{2} \mathrm{H}_{3}\right.$ loss $)$ for 11. To the best of our knowledge, the dissociation chemistry of the other six $\mathrm{PyC}_{2} \mathrm{H}_{5}^{+}$distonic ions 4-9 has not been investigated.

Under the present low-energy experimental conditions, 1 displays very characteristic CID chemistry (Figure 5a). It shows a unique and reasonably abundant fragment of $m / z 78\left(\mathrm{C}_{2} \mathrm{H}_{5}\right.$ loss), whereas no fragments of $\mathrm{m} / \mathrm{z} 92$ and 65 are produced. On the other hand, the CID spectra for both 2 and 3 (Figure $5 b$ and c) show very abundant $\mathrm{m} / z 92\left(\mathrm{CH}_{3}^{\prime}\right.$ loss $), 79$ $\left(\mathrm{C}_{2} \mathrm{H}_{4}\right.$ loss), and 65 (probably $\mathrm{CH}_{3}$ plus HCN loss) fragments with variable abundances, whereas the $m / z$ 78 fragment is very low in abundance in both spectra. The great abundance of the $m / z 78$ ion $\left(\mathrm{C}_{2} \mathrm{H}_{5}\right.$ loss) for 1 is proportioned by the much greater stability of the 2-pyridinium ion owing to the stabilizing effect of the neighboring pyridine nitrogen lone pair (eq 5) [23], an

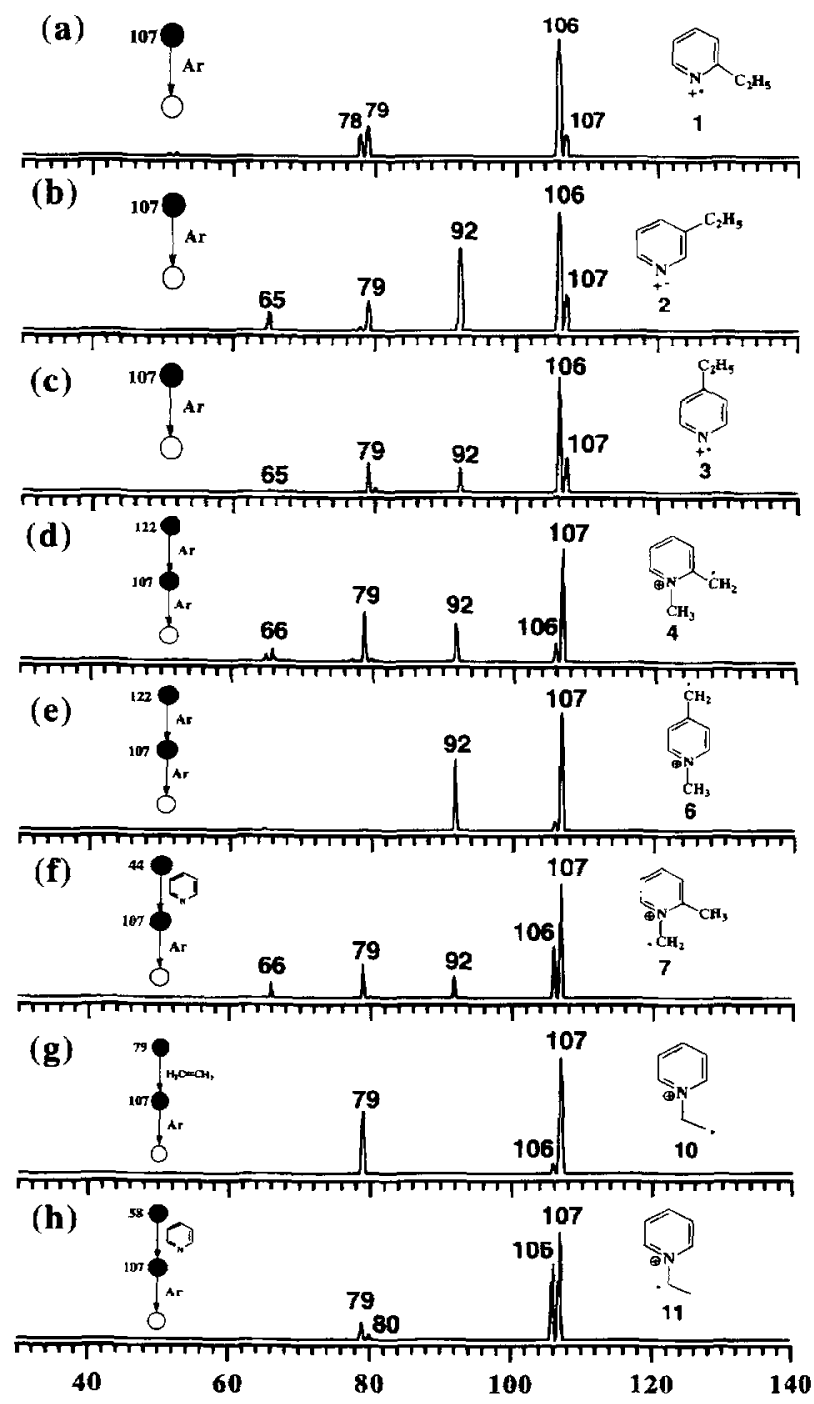

Figure 5. (a)-(h) $\mathrm{MS}^{2} \mathrm{CID}$ product ion spectra of several $\mathrm{PyC}_{2} \mathrm{H}_{5}^{+\cdot}$ ions. The corresponding spectra of 5 and 8-9 closely resemble those of $6(e)$ and $7(f)$, respectively, and are not shown. effect recently confirmed by $\mathrm{MS}^{2}$ experiments and high-level ab initio calculations (Gozzo, F. C.; Eberlin, M. N., unpublished). There are some significant differences in the relative abundances of the fragments in the CID spectra of 2 and 3 (Figures $5 \mathrm{~b}$ and $\mathrm{c}$ ), which appear to be relevant for their characterization because the very same experimental conditions (such as lens settings, argon pressure, and collision energies) were applied to dissociate both isomers during the tandemin-space pentaquadrupole $\mathrm{MS}^{2}$ experiments.<smiles>CCc1ccccn1</smiles><smiles>CCCC</smiles><smiles>[c-]1ccccn1</smiles>

Ions 7-9 show very similar CID spectra, as exemplified for 7 in Figures 3 and 5f. Figure $3 a$ shows the three-dimensional spectrum that was acquired by mass-selection of the $\mathrm{CH}_{2}-\mathrm{O}-\mathrm{CH}_{2}^{+}$ion of $\mathrm{m} / z$ 44 in Q1 and by sequential scan of both $\mathrm{Q3}$ and Q5, while ion-molecule reactions were performed with 2-methyl pyridine and CID with argon in $\mathrm{q} 2$ and $\mathrm{q} 4$, respectively. This three-dimensional spectrum nicely exemplifies the applicability of $\mathrm{MS}^{3}$ intermediate-product domain scan [9] for the study of ion-molecule reactions. A detailed view of the whole process is presented because the surviving reactant ion $(m / z$ 44) and all the products of the ion-molecule reactions $(\mathrm{m} / z 94$ and 107) are displayed along the diagonal line in which equal mass-to-charge ratios at Q3 and Q5 are selected. Additionally, the CID fragments of each reaction product are seen across the horizontal Q5 axis, which can therefore be used for their structural characterization. A clearer view of each dissociation spectrum can be obtained by extraction along the Q5 axis (fixed Q3 mass-to-charge ratios), which produces twodimensional sequential product ion spectra, as exemplified for the $m / z 107$ product in Figure $3 b$ (to facilitate comparison, Figure $3 \mathrm{~b}$ also was included in Figure 5). On the other hand, the product ion spectrum (Figure 3c) can be reconstructed by projection of the threedimensional spectrum toward the Q5 axis. Projection is performed by addition of the abundance of the corresponding fragments to the abundance of the surviving ions. Hence, the effect of depletion of the relative abundance of the product ions caused by dissociation in q4 is canceled out, and the correct yields of the ion-molecule products are displayed. Note that the three-dimensional spectrum (Figure $3 a$ ) also permits one to verify the identity of the reactant ion $\left({ }^{+} \mathrm{CH}_{2}-\mathrm{O}-\mathrm{CH}_{2}, m / z 44\right)$, which dissociates as expected [24] by hydrogen atom loss, but mainly by methyl radical loss to give products of $m / z 43$ and 29 , respectively.

Comparison of Figure $5 f$ with Figure $5 b$ and $c$ show that the distonic ions 7-9 and the conventional ions 2-3 dissociate mainly to the same ionic fragments. Ions 7-9, however, display a unique fragment of $\mathrm{m} / \mathrm{z} 66$ 
(Figure 5f), whereas 2 and 3 (Figure $5 \mathrm{~b}$ and $\mathrm{c}$ ) show instead a unique fragment of $m / z 65$. This characteristic dissociation chemistry, as well as that of 1 (Figure 5a), make the two subcategories of $\mathrm{PyC}_{2} \mathrm{H}_{5}^{+\cdot}$ isomers 1-3 and 7-9 readily distinguishable by low-energy CID. Rationalizations for the contrasting dissociation behavior of 7-9 and 2-3 that leads, respectively, to ions of $m / z 65$ or 66 are presented in eqs 6 and 7 .
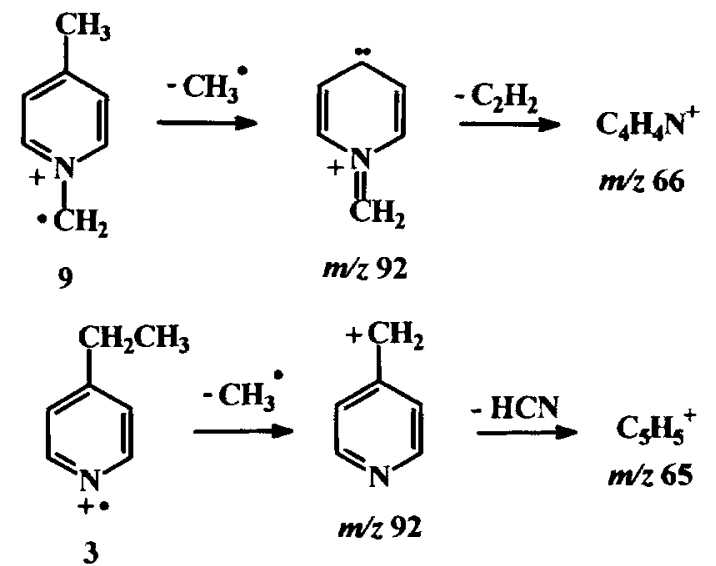

The CID spectra of 4-6 are also quite interesting. Ions 5 and 6 (Figure 5e) display very similar and also characteristic dissociation chemistry, which is dominated by methyl radical loss to give products of $\mathrm{m} / \mathrm{z}$ 92. The ortho isomer 4 (Figure $5 \mathrm{~d}$ ), on the other hand, displays a quite distinct CID spectrum, which is similar to that of 7. Note that the $m / z 66$ fragment was found to be unique for 7-9 (Figure 5f). The fact that 4 behaves very differently from 5 and $\mathbf{6}$ and that its CID spectrum shows the $m / z 66$ fragment while it closely resembles that of 7 , indicates the occurrence of the $4 \rightarrow 7$ isomerization (eq 8) preceding or during the course of collisions.<smiles>[C+]c1cccc[n+]1C</smiles>

4

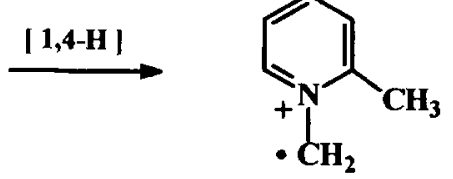

7
Ions 10 (Figure 5g) and 11 (Figure 5h) display very characteristic low-energy CID chemistry, which allows straightforward differentiation between them and also from all the other $\mathrm{PyC}_{2} \mathrm{H}_{5}^{+\cdot}$ isomers that were investigated. Although practically the same fragments of $m / z$ 106 and 79 are displayed for both isomers, the differences in their relative abundances are remarkable. The spectrum of $\mathbf{1 0}$ (Figure $5 \mathrm{~g}$ ) is largely dominated by the $m / z 79$ fragment, whereas the fragment of $m / z 106$ dominates the spectrum of $\mathbf{1 1}$ (Figure $5 i$ ). In addition, a minor but unique fragment of $m / z 80$, which is the characteristic fragment in the high-energy CID spectrum [11], is also observed for 11. This characteristic CID chemistry can be associated directly with the $\alpha$ - and $\beta$-distonic structures. The $\beta$-position (relative to the pyridine ring) of the radical site in $\mathbf{1 0}$ makes available two competitive direct $\alpha$-cleavage dissociations that could occur either by loss of a hydrogen atom or neutral ethene (eq 9). The dominance of the $m / z 79$ fragment indicates that loss of ethene is by far the most favorable dissociation process, which appears to be typical for $\beta$-distonic ions [25]. On the other hand, the only direct $\alpha$-cleavage dissociation available for the $\alpha$-distonic ion $\mathbf{1 1}$ is hydrogen atom loss (eq 10), which accounts for the great abundance of the $\mathrm{m} / \mathrm{z}$ 106 fragment.

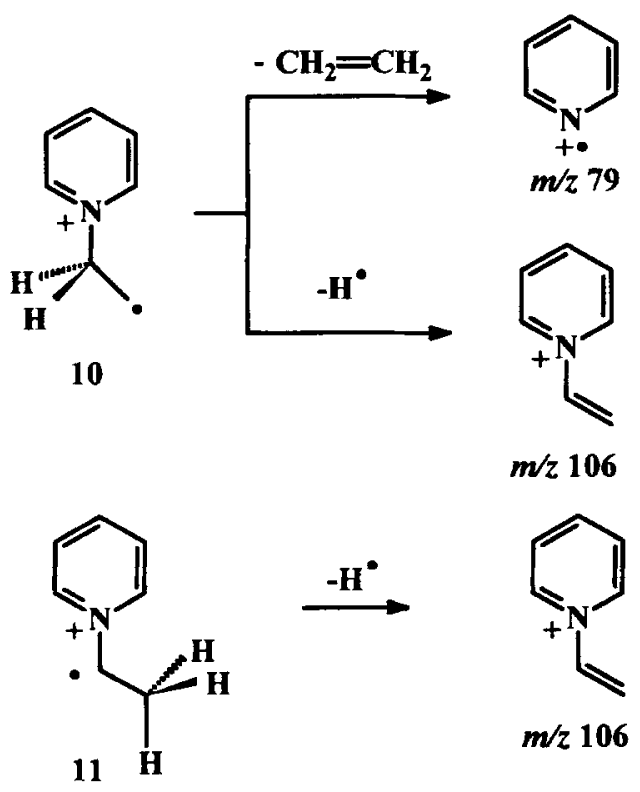

Ion-molecule chemistry. Gross and co-workers [11] recently showed that under high-pressure FTMS conditions, 10 reacts extensively with the diradical molecule of oxygen to yield an abundant adduct of $m / z 139$. This reaction was proposed to involve the highly localized $\beta$-methylene radical site of $\mathbf{1 0}$ and to take place via radical coupling (eq 11). The $\alpha$-distonic ion 11, on the other hand, was shown to be unreactive toward oxygen, and extensive odd-spin delocalization through the neighboring pyridine ring was proposed as a possible explanation for its lack of reactivity.

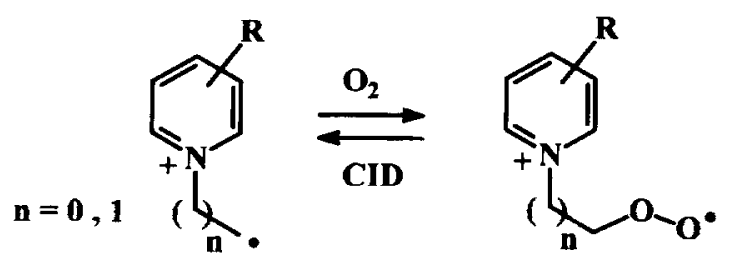

In the present study, the reactions of all $11 \mathrm{PyC}_{2} \mathrm{H}_{5}^{+*}$ 1-11 (and two chlorine analogs) with oxygen were investigated and the applicability for isomer distinction was tested. The results show that only the distonic 


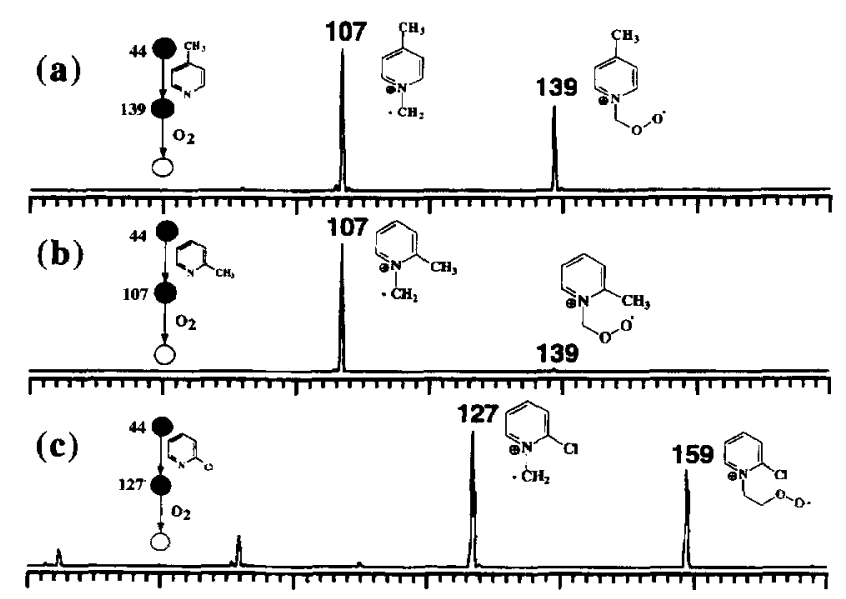

Figure 6. Sequential product ion spectra obtained by performing pentaquadrupole triple-stage experiments in which ions (a) 9 (b) 7, and (c) 12 were produced in q2 via ion-molecule reactions between mass-selected ${ }^{\circ} \mathrm{CH}_{2}-\mathrm{O}-\mathrm{CH}_{2}^{+}$ions $(\mathrm{m} / \mathrm{z} 44)$ and the appropriate pyridines, and reacted further in $\mathrm{q} 4$ with $\mathrm{O}_{2}$. The spectra of 8 and 13 closely resemble those of $9(\mathbf{b})$ and $12(c)$ and are not shown.

ions 8 (Figure 6a), 9, and 10 (Figure 4e) react extensively with oxygen by adduct formation (eq 11). The other distonic ions 4, 5, 6, 7, and 11 and the three conventional ions 1-3 were practically or completely unreactive; they undergo only partial dissociation under the very low-energy collision conditions applied in the ion-molecule reaction experiments. The fact that the two $\alpha$-distonic ions $\mathbf{8}$ and $\mathbf{9}$ form abundant adducts with oxygen is interesting because it argues against the previous proposal [11] that ring-spin delocalization suppresses the reactivity of $N$-methylene $\alpha$-distonic pyridinium ions.

The fact that the ortho-methyl substituted ion 7 (Figure $6 \mathrm{~b}$ ) is practically unreactive with oxygen, whereas its meta and para analogs 8 and 9 (Figure 6a) react readily, is also interesting. Such a drastic change in reactivity could indicate that adduct formation is very sensitive to steric hindrance on the methylene radical site, which may be important for 7 because of the ortho-methyl pyridine substituent and for $\mathbf{1 1}$ because of the neighboring $\alpha$-methyl substituent. However, both the chlorine analogs 12 and 13 (a CI-CID sequence similar to that used for 7-9 was applied in generating 12-13; see text) react extensively with oxygen by radical coupling (Figure 6c). The extensive reactivity of the ion that bears the bulky ortho-chlorine atom rules out "ortho"-steric hindrance effects. As already mentioned, the isomerization process $4 \rightarrow 7$ was indicated by the CID spectra. Taking into account that 4 was found to be unreactive, it is suggested that the reverse process $7 \rightarrow \mathbf{4}$ is the most consistent explanation for the low reactivity of 7 . Interconversion between the two isomers appears therefore to be facile, which also has been evidenced by the ab initio calculations (see subsequent text).<smiles>C[n+]1ccccc1Cl</smiles>

12<smiles>[CH2-][n+]1cccc(Cl)c1</smiles>

13

\section{Structure of the $\mathrm{O}_{2}$ Adducts}

The dissociation chemistry of the products of the radical coupling reaction with oxygen were investigated via $\mathrm{MS}^{3}$ experiments as exemplified in Figure 4g. To perform these experiments, the reactant ions (7-11) were generated via ion-molecule reactions performed under much less effective CI conditions. The oxygen adducts were found to dissociate extensively and exclusively by $\mathrm{O}_{2}$ loss and most likely reformed the reactant ion (eq 11). Note, however, that a great amount of the precursor ion survived the $15-\mathrm{eV}$ collisions (Figure 4f), whereas complete dissociation is observed for several loosely bound species under similar collision conditions $[10 \mathrm{c}, \mathrm{f}]$. This observation strongly indicates that the oxygen adducts are covalently bound species. Such dissociation chemistry, although limited in providing structural formation on the adducts, is entirely consistent with their proposed structures, especially if one considers that release of stable neutral molecules such as of $\mathrm{O}_{2}$ also should be quite thermodynamically favorable processes.

\section{Ab Initio Calculations}

Relative stabilities. The relative $a b$ initio energies of the $\mathrm{PyC}_{2} \mathrm{H}_{5}^{+\cdot}$ ions are presented in Table 1. The results show that all the distonic ions (4-11) are notably more stable than the conventional radical cations $1-3$. These are, therefore, additional examples of the great stability of distonic ions. It is also interesting to note that, although considerable less thermodynamically stable, the characteristic CID and ion-molecule chemistry of 1-3 indicate that they are "kinetically" stable gas-phase species, which must lie in deep potential wells that considerably hamper their isomerization to the more stable isomers 4-11.

Ions 4-6 were found by the calculations to be slightly more stable than their corresponding isomers 7-9. The $4 \rightarrow 7$ isomerization indicated by the CID spectra is predicted by the calculations to be endothermic by only $5.3 \mathrm{kcal} / \mathrm{mol}$; therefore it could take place under collisional excitation and be driven by lower energy dissociation thresholds of 7 . On the other hand, the reverse $7 \rightarrow 4$ isomerization indicated by the ion-molecule reaction experiments is exothermic (by $-5.3 \mathrm{kcal} / \mathrm{mol}$ ) and therefore thermodynamically favorable. The apparently facile interconversion between these isomers indicates low activation barriers for both 
Table 1. Total, ZPE, and relative energies from ab initio full structure optimization calculations of the $\mathrm{PyC}_{2} \mathrm{H}_{5}^{+} \cdot$ ions

\begin{tabular}{rccc} 
Ion & $\begin{array}{c}\text { ROMP2/6-31G(d,p)//6-31G(d, p) } \\
\text { (hartrees) }\end{array}$ & $\begin{array}{c}\mathrm{ZPE}^{\mathrm{b}} \\
(\mathrm{kcal} / \mathrm{mol})\end{array}$ & $\begin{array}{c}\text { Relative energy } \\
(\mathrm{kcal} / \mathrm{mol})\end{array}$ \\
\hline 1 & -325.57155 & 86.1 & 28.9 \\
2 & -325.56268 & 86.2 & 34.6 \\
3 & -325.56705 & 86.1 & 31.8 \\
4 & -325.61590 & 86.5 & 1.5 \\
5 & -325.61473 & 85.8 & 1.6 \\
6 & -325.61832 & 86.5 & 0 \\
7 & -325.60615 & 85.7 & 6.8 \\
8 & -325.60574 & 85.3 & 6.7 \\
9 & -325.60603 & 85.3 & 6.5 \\
10 & -325.59725 & 87.5 & 14.3 \\
11 & -325.60670 & 85.9 & 6.7 \\
\hline
\end{tabular}

ROMP2 and ROHF calculations were performed because excessively high spin contaminations (greater than 0.80 ) were verified in several cases when unrestricted second-order Møller-Plesset and unrestricted Hartree-Fock calculations were applied.

Scaled by 0.89 .

Including ZPE.

processes. The fact that interconversion is observed only for the ortho-isomers 4 and 7 can be rationalized as an interesting ortho effect that involves the spatial proximity of the two interacting methylene and methyl groups (eq 8), whereas meta and para isomers do not undergo intramolecular hydrogen shifts. Note also that the $\beta$-distonic ion 10 is found to be $7.6 \mathrm{kcal} / \mathrm{mol}$ less stable than its $\alpha$-isomer 11. However, contrary to the $[1,4-\mathrm{H}]$ shift in the $4 \rightleftarrows 7$ case, the $[1,2-\mathrm{H}]$ shift appears to involve a relatively high-energy barrier, which is evidenced from the fact that $\mathbf{1 0}$ and $\mathbf{1 1}$ display very distinctive CID and ion-molecule reaction chemistry.

Classification of the $\mathrm{PyC}_{2} \mathrm{H}_{5}^{+{ }^{+}}$ions as conventional or distonic. Figure 7 shows the $\mathrm{ab}$ initio odd-spin and Mulliken charge densities of all $11 \mathrm{PyC}_{2} \mathrm{H}_{5}^{+\cdot}$ isomers. When the common definition [12] is applied, 1-3 are classified clearly as conventional radical cations because ionization most favorably involves abstraction of an electron from the nitrogen lone pair and/or from the pyridine ring; hence charge and spin densities must be largely on the ring. As expected, this trend is exactly what is predicted by the calculations (Figure 7). Ion $\mathbf{1 0}$ also is classified easily as distonic because the $\beta$-radical site is formally isolated by a saturated methylene group from the pyridine ring in which the positive charge should be localized. The ab initio results for $\mathbf{1 0}$ confirm this expectation by presenting a very characteristic distonic distribution (Figure 7).

Although for 7, 8, 9, and 11 there is no formal electronic representation in which both the charge and the unpaired electron can be placed at the same atom, spin delocalization through the pyridine ring still could be postulated by taking into account the proximity of the methylene group to the pyridine ring, the coplanarity of the system, and the appropriate symmetry of the $p$-orbitals; hence their classification as distonic ions by the "spatially separated" definition could be questioned. The $a b$ initio spin densities for ions 7-9 and $\mathbf{1 1}$ are, however, heavily on the $\alpha$-methylene group while extensive charge delocalization is observed. It is widely known that charge densities may vary considerably depending on the method applied. By using the Mulliken, Merz-Singh-Kollman (MSK), and natural bond orbital (NBO) [26] methods implemented in
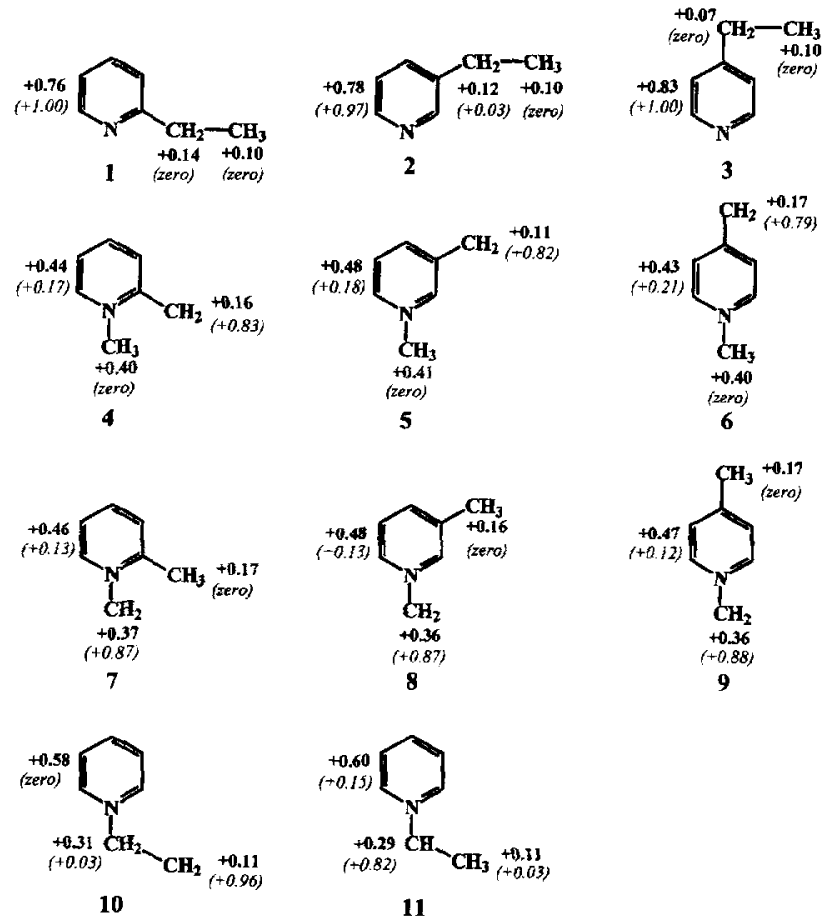

Figure 7. Ab initio Mulliken charge (bold numerals) and spin densities (italic numerals in parentheses) for ions 1-11 obtained at the ROMP2/6-31G(d,p)//6-31G(d,p) level of theory. The values of the hydrogens on the substituents were summed onto the heavy atoms, whereas for simplicity the summation of the values for all the atoms of the pyridine ring are shown. 
Gaussian94 [15], the positive charge is observed for all methods, but particularly for the MSK and NBO methods, to be largely on the methylpyridine ring of ions 7-9 and 11, as exemplified for 7 in Figure 8. This observation, together with no significant odd-spin delocalization throughout the aromatic ring, firmly corroborates the "spatially separated" distonic structure.

The case of 4-6, particularly of 4 and 6 , is considerably more complex. Although their analogs $\mathrm{N}$ protonated methylene pyridinium ions $\left(\mathrm{H}_{2} \mathrm{C}-\mathrm{C}_{5} \mathrm{H}_{4} \mathrm{NH}^{+}\right)$already have been classified and characterized as distonic [27], one can draw for these ions as well as for 4 and 6 a resonance electronic structure (b) in which the charge and spin sites are not "spatially separated," but are formally localized at the nitrogen atom (eq 12). (a)<smiles>[CH2-][n+]1ccc(C)cc1</smiles><smiles>C=C1C=C[N+](C)C=C1</smiles>

(b)
The equivalent resonance structure cannot be drawn for the meta isomer 5; hence its classification as distonic appears to be more straightforward, although, as for 7-9 and 11, ring delocalization could be postulated. However, aromaticity is lost for 4-6 when the odd electron is delocalized through the pyridine ring (eq 12); hence the distonic form (a) could be favored. On the other hand, one could argue that 4 and 6 are ionized forms of conventional neutrals [eq 13, form (a)] and hence they should not be classified as distonic according to the original definition [13]. However, the neutral precursors also can be represented in aromatic zwitterionic forms [eq 13, form (b)]; hence the ambiguity still remains. (a)<smiles>C=C1C=CN(C)C=C1</smiles>

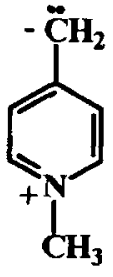

(b)
The ab initio results for 4-6 are indeed interesting and clarifying (Figure 7). Rather surprisingly, all of these ions (and the other distonic ions 7-11) show very similar spin and charge distributions. Spin densities are with no exceptions largely on the methylene group, whereas the positive charge is concentrated mainly on the pyridine ring and $N$-methyl substituent. These theoretical results strongly support form (a) and rule out any important contribution of form (b) (eq 12),

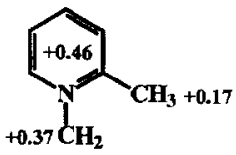

(a)

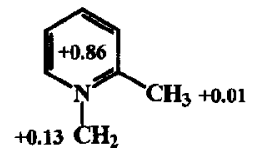

(b)

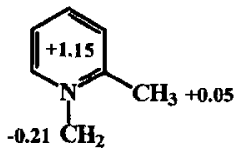

(c)
Figure 8. (a) Mulliken, (b) MSK, and (c) NBO charge densities of 7. Note that all methods, but particularly MSK and NBO, place the charge largely on the methylpyridine ring.

which allows one to propose the classification of all three ions $4-6$ as distonic ions.

The ab initio charge and spin densities also are important for a better understanding of the ion-molecule chemistry of the $\mathrm{PyC}_{2} \mathrm{H}_{5}^{+\cdot}$ ions. Ions 7-9 and 11, as already mentioned, show no significant odd-spin delocalization throughout the pyridine ring. When we consider that 8 and 9 react extensively by radical coupling with oxygen, ring-spin delocalization is therefore ruled out as the main factor that suppresses the oxygen coupling reactivity of 11 . The possibility of isomerization of 11 to 10 also is ruled out both by the theoretical and experimental results, as already discussed. It is therefore apparent that high spin densities on the formal radical site are not the main or the only factor that drives the radical coupling reaction of $N$ methylene pyridinium distonic ions with oxygen. Additionally, the lack of reactivity of $\mathbf{1 1}$ may be understood only as an indication that the oxygen coupling reaction is highly sensitive to substitution on the $\mathrm{N}-\mathrm{CH}_{2}$ site most likely due to " $\alpha$ "-steric hindrance effects. Other results from our laboratory (Pimpim, R. S.; Augusti, R.; Eberlin, M. N., unpublished) that involve several types of distonic ions indicate that the oxygen coupling reaction occurs preferentially for distonic ions that bear unsubstituted methylene radical sites directly bound to heteroatoms such as nitrogen and sulfur.

\section{Conclusion}

By application of judicious combinations of $\mathrm{EI}$ and $\mathrm{CI}$, $\mathrm{CID}$, and mass-selected ion-molecule reactions and by taking advantage of the outstanding capabilities of the pentaquadrupole mass spectrometer to perform multiple stage $\left(\mathrm{MS}^{2}\right.$ and $\mathrm{MS}^{3}$ ) mass spectrometric experiments, $11 \mathrm{PyC}_{2} \mathrm{H}_{5}^{+-}$isomers (1-11) have been generated and, in most cases, clearly have been characterized in the gas phase. Extensive loss of an ethyl radical to yield the 2-pyridyl cation $(\mathrm{m} / z$ 78) and the lack of the $m / z 92$ fragment characterize the unique dissociation chemistry of 1 . No dissociation to $m / z 92$ is also a characteristic of $\mathbf{1 0}$ and $\mathbf{1 1}$. In addition, $\mathbf{1 0}$ dissociates minimally by hydrogen atom loss to give the $\mathrm{m} / \mathrm{z} 106$ product and extensively by ethene loss to give the $\mathrm{m} / \mathrm{z}$ 79 product, whereas the opposite trend is observed for 11, which also shows a minor but unique fragment of $m / z$ 80. Ions 7-9 and 2-3 display mainly the same series of fragments of $m / z 106,92$, and 79. However, a unique fragment of $m / z$ displayed by $7-9$ and of 
$m / z 65$ displayed by 2-3 permit their clear differentiation. Under carefully controlled low-energy CID conditions, significant differences in the relative abundances of the CID fragments of 2 and 3 are observed. Ion 4 displays a CID spectrum that closely resembles that of 7 , which indicates the occurrence of $4 \rightarrow 7$ isomerization, which ab initio calculations indicate is a collision-induced process. Although 7-9 are indistinguishable by $\mathrm{CID}$, the extensive oxygen coupling ion-molecule reactivity of 8-9 and the lack of such reactivity for 7 easily differentiate 7 from $8-9$. The ortho-isomer $\mathbf{7}$ is unreactive most likely because it is an unstable species that undergoes rapid isomerization to the more stable ion 4 , as predicted by the ab initio calculations. Reactions with oxygen also allow easy distinction between 10 and 11 because the former reacts extensively, whereas $\mathbf{1 1}$ is completely unreactive. The radical coupling reaction with $\mathrm{O}_{2}$ appears to be general for the specific class of $\mathrm{N}$-methylene pyridinium distonic ions $\left(\mathrm{R}-\mathrm{C}_{4} \mathrm{H}_{4} \mathrm{~N}^{+}-\mathrm{CH}_{2}\right)$ that bear no ortho-alkyl or $\alpha$-methylene substituents. The results for the $\mathrm{PyC}_{2} \mathrm{H}_{5}^{+\cdot}$ ions nicely exemplify the power of multiple-stage mass spectrometry to produce, isolate, characterize, and study the chemistry of a variety of ions in the gas phase.

The $a b$ initio calculations show a considerably greater thermodynamic stability for the distonic ions 4-11 when compared to the conventional radical cations 1-3, a trend also observed for several other isomeric systems. Although less thermodynamically stable, the conventional ions 1-3 are "kinetically" stable toward isomerization to 4-11, as indicated by their characteristic CID and ion-molecule reaction chemistry. The ab initio charge and odd-spin densities were invaluable for characterization of the distonic or conventional radical cation structures of the $\mathrm{PyC}_{2} \mathrm{H}_{5}^{+*}$ isomers.

\section{Acknowledgments}

This work was supported by the Research Support Foundation of the State of São Paulo (FAPESP) and the Brazilian National Research Council (CNPq).

\section{References}

1. (a) Bowers, M. T., Ed.; Gas Phase Ion Chemistry; Academic Press: New York, 1979; (b) McLafferty, F. W.; Turecek, F. Interpretation of Mass Spectra; HD Science: New York, 1993; (c) Westmore, J. B.; Alauddin, M. M. Mass Spectrom. Rev. 1986, 5, 381; (d) Vairamani, M.; Ali Mirza, U.; Srinivas, R. Mass Spectrom. Rev. 1990, 9, 235.

2. (a) Cooks, R. G., Ed. Collision Spectroscopy; Plenum Press: New York, 1979; (b) Levsen, K.; Schwarz, H. Mass Spectrom. Rev. 1983, 2, 77; (c) Holmes, J. L. Org. Mass Spectrom. 1985, 20, 169.

3. (a) Gross, M. L.; McLafferty, F. W. J. Am. Chem. Soc. 1971, 93, 1267; (b) Gross, M. L.; Lin, P-H.; Franklin, S. J. Anal. Chem. 1972, 44, 974; (c) Staley, R. H.; Corderman, R. R.; Foster, M. S.; Beauchamp, J. L. I. Am. Chem. Soc. 1974, 96, 1260; (d) Bouma, W. J.; MacLeod, J. K.; Radom, L. Adv. Mass Spectrom.
1980, 8A, 178; (e) Lay, J. O., Jr.; Gross, M. L. I. Am. Chem. Soc. 1983, 105, 3445; (f) Caserio, M. C.; Kim, J. K. J. Am. Chem. Soc. 1983, 105, 6896; (g) Wronka, J.; Ridge, D. P. J. Am. Chem. Soc. 1984, 106, 67; (h) Fetterolf, D. D.; Yost, R. A. Org. Mass Spectrom. 1984, 19, 104; (i) Kinter, M. T.; Bursey, M. M. J. Am. Chem. Soc. 1986, 108, 1797; (j) Kascheres, C.; Cooks, R. G. Anal. Chim. Acta 1988, 223; (k) Wittneben, D; Grützmacher, H.-F. Int. J. Mass Spectrom. Ion Processes 1990, 100, 545; (1) Malenka, S.; Brodbelt, J.; Pope, K. J. Am. Soc. Mass Spectrom. 1991, 2, 212; (m) Kenttämaa, H. I.; Cooks, R. G. J. Am. Chem. Soc. 1989, 111, 4122; (n) Wesdemiotis, C.; Zhang, M.-Y.; McLafferty, F. W. Org. Mass Spectrom. 1991, 26, 671; (o) Heath, T. G.; Allison, J.; Watson, J. T. J. Am. Soc. Mass Spectrom. 1991, 2, 270.

4. Eberlin, M. N.; Cooks, R. G. Org. Mass Spectrom. 1993, $28,679$.

5. (a) Gozzo, F. C.; Eberlin, M. N. Proceedings of the 41th ASMS Conference on Mass Spectrometry and Allied Topics, 1993; $\mathrm{p}$ 974a; (b) Gozzo, F. C.; Sorrilha, A. E. P. M.; Eberlin, M. N. J. Chem. Soc. Perkin Trans. 2, 1996, 587.

6. Beasley, B. J.; Smith, R. L.; Kenttämaa, H. I. J. Mass Spectrom. 1995, 30, 384.

7. (a) McLafferty, F. W. Tandem Mass Spectrometry; Wiley: New York, 1983; (b) Bush, K. L.; Glish, G. L.; McLuckey, S. A. Mass Spectrometry / Mass Spectrometry: Techniques and Applications of Tandem Mass Spectrometry; VCH: New York, 1989.

8. (a) Schwartz, J. C.; Schey, K. L.; Cooks, R. G. Int. J. Mass Spectrom. Ion Processes 1990, 101, 1; (b) Juliano, V. F.; Gozzo, F. C.; Eberlin, M. N.; Kascheres, C.; Lago, C. L. Anal. Chem. 1996, 68, 1328.

9. Schwartz, J. C.; Wade, A. P.; Enke, C. G.; Cooks, R. G. Anal. Chem. 1990, 62, 1809.

10. (a) Shay, B. J.; Eberlin, M. N.; Cooks, R. G.; Wesdemiotis, C. J. Am. Soc. Mass Spectrom. 1992, 3, 518; (b) Kotiaho, T.; Shay, B. J.; Cooks, R. G.; Eberlin, M. N. J. Am. Chem. Soc. 1993, 115, 1004; (c) Eberlin, M. N.; Majumdar, T. K.; Cooks, R. G. J. Am. Chem. Soc. 1992, 114, 2884; (d) Eberlin, M. N.; Cooks, R. G. I. Am. Chem. Soc. 1993, 115, 9226; (e) Eberlin, M. N.; Kotiaho, T.; Shay, B. J.; Yang, S. S.; Cooks, R. G. J. Am. Chem. Soc. 1994, 116, 2457; (f) Bortolini, O.; Yang, S. S.; Cooks, R. G. Org. Mass Spectrom. 1993, 28, 1313; (g) Eberlin, M. N.; Morgon, N. H.; Yang, S. S.; Shay, B. J.; Cooks, R. G. J. Am. Soc. Mass Spectrom. 1995, 6, 1; (h) Gozzo, F. C.; Eberlin, M. N. J. Am. Soc. Mass Spectrom. 1995, 6, 554; (i) Gozzo, F. C.; Eberlin, M. N. J. Mass Spectrom. 1995, 30, 1553; (j) Gozzo, F. C.; Eberlin, M. N. J. Am. Soc. Mass Spectrom. 1995, 6, 554.

11. Yu, S. J.; Holliman, C. L.; Rempel, D. L.; Gross, M. L. J. Am. Chem. Soc. 1993, 115, 9676.

12. (a) Hammerum, S. Mass Spectrom. Rev. 1988, 7, 123; (b) Bouchoux, G. Mass Spectrom. Rev. 1988, 7, 203; (c) Stirk, K. M.; Kiminkinen, M. L. K,; Kenttämaa, H. I. Chem. Rev. 1992, 92; (d) Kenttämaa, H. I. Org. Mass Spectrom. 1994, $29,1$.

13. (a) Yates, B. F.; Bouma, W. J.; Radom, L. J. Am. Chem. Soc. 1984, 106, 5805; (b) Radom, L.; Bouma, W. J.; Nobes, R. H.; Yates, B. F. Pure Appl. Chem. 1984, 56, 1831; (c) Yates, B. F.; Bouma, W. J.; Radom, L. Tetrahedron 1986, 42, 6225.

14. (a) Lewis, G. N. J. Am. Chem. Soc. 1916, 38, 762; (b) Simonetta, M. In Structural Chemistry and Molecular Biology; Rich, A.; Davidson, N., Eds.; Freeman: San Francisco, 1968; p 769; (c) Carey, F. A.; Sundberg, R. J. Advanced Organic Chemistry; Plenum Press: New York, 1984.

15. Frisch, M. J.; Trucks, G. W.; Schlegel, H. B.; Gill, P. M. W.; Johnson, B. G.; Robb, M. A.; Cheeseman, J. R.; Keith, T.; Petersson, G. A.; Montgomery, J. A.; Raghavachari, K.; AlLaham, M. A.; Zakrzewski, V. G.; Ortiz, J. V.; Foresman, J. B.; Peng, C. Y.; Ayala, P. Y.; Chen, W.; Wong, M. W.; Andres, J. L.; Replogle, E. S.; Gomperts, R.; Martin, R. L.; Fox, D. J.; Binkley, J. S.; Defrees, D. J.; Baker, J.; Stewart, J. P.; Head- 
Gordon, M.; Gonzalez, C.; Pople, J. A. Gaussian94, revision B.3; Gaussian, Inc.: Pittsburgh, PA, 1995.

16. (a) Hehre, W. J.; Ditchfield, R.; Pople, J. A. J. Chem. Phys. 1972, 56, 2257; (b) Hariharan, P. C.; Pople, J. A. Theor. Chim. Acta 1973, 72, 650; (c) Gordon, M. S. Chem. Phys. Lett. 1980, 76, 163; (d) Frisch, M. J.; Pople, J. A.; Binkley, J. S. J. Chem. Phys. 1984, 80, 3265.

17. Maller, C.; Plesset, M. S. Phys. Rev. 1934, 46, 618.

18. Xmol, version 1.3.1, Minnesota Supercomputer Center, Inc., Minneapolis, MN, 1993.

19. Bateman, R. H.; Brown, J.; Lefevere, M.; Flammang, R.; Van Haverbeke, Y. Int. J. Mass Spectrom. Ion Processes 1992, 115, 205.

20. (a) Porter, Q. N. Mass Spectrometry of Heterocyclic Compounds; Wiley: New York, 1985; p 633; (b) Larsen, E,; Egsgaard, H.; Holmen, H. Organic Mass Spectrom. 1978, 13, 417.
21. (a) de Koster, C. G.; van Houte, J. J.; van Thuijl, J. Int. I. Mass Spectrom. Ion Processes 1990, 98, 178; (b) Yu, S. J.; Gross, M. L.; Fountain, K. R. J. Am. Soc. Mass Spectrom. 1993, 4, 117.

22. van de Guchte, W. J.; van der Hart, W. J. Org. Mass Spectrom. 1990, 25, 309.

23. (a) Lewis, E. S.; Cooper, J. E. J. Am. Chem. Soc. 1992, 84, 3847; (b) Kauffmann, T.; Boettcher, F.-P. Chem. Ber. 1962, 95, 949.

24. (a) Van de Sande, C. C.; McLafferty, F. W. J. Am. Chem. Soc. 1975, 97, 4613; (b) Mabud, Md. A.; Ast, T.; Verma, S.; Jiang, Y.-X.; Cooks, R. G. J. Am. Chem. Soc. 1987, 109, 7597.

25. Bjørnholm, T.; Hammerum, S.; Kuck, D. J. Am. Chem. Soc. 1988, 110, 3862.

26. Glendening, E. D.; Reed, A. E.; Carpenter, J. E; Weinhold, F. NBO version 3.1.

27. Wysocki, V. H.; Kenttämaa, H. I. J. Am. Chem. Soc. 1990, 112, 5110. 